\title{
A Mathematical Model of the Drying Process
}

\begin{abstract}
A. K. Haghi
A convective drying model is proposed which may be used to describe the drying behavior of leather. Using this model, the calculated transient leather temperature agrees well with experimental values. Variations in temperature and moisture content distribution are solved using the finite-difference method. The effects of operation parameters, such as temperature and humidity in the dryer, initial moisture content of the leather, and heat and mass transfer coefficients are examined using the model.
\end{abstract}

Keywords: convectiv drying model, leather, transient temperature field.

\section{Introduction}

Among the many processes that are performed in the leather industry, convective drying has an essential role. Leather fabrication has become an important industrial development worldwide, similar to other technologically advanced process industries. Some of the unit operations involved in this industry, especially the drying process, are still based on empiricism and tradition, with very little use of scientific principles [1-4].

Many researchers have studied the drying process through a variety of mathematical models [5-10]. Beard [5] assumed that leather can consist of two layers, one dry and one wet layer. However, his analysis did not describe the details of what was going on inside the leather. Also, he used two experimental constants to fit his data to the experimental results of the measured temperature variation inside the dryer.

In this study, the mathematical model developed by Nordon [9] has been modified to determine the transient temperature and moisture concentration distribution of leather in a dryer. Also, the distributions of temperature and moisture concentration are calculated using the finite-difference method. The effects of many operating parameters such as dryer temperature, humidity, and initial moisture content of the leather have been examined.

\section{Mathematical model}

The mathematical model derived by Nordon is used with small modifications. The resulting differential equations are derived as

$$
D \frac{\partial C_{\mathrm{A}}}{\partial x^{2}}=\frac{\partial C_{\mathrm{F}}}{\partial t}+\frac{\partial C_{\mathrm{A}}}{\partial t}
$$

and

$$
k \frac{\partial^{2} T}{\partial x^{2}}=\rho C_{\mathrm{p}} \frac{\partial T}{\partial t}-\lambda \frac{\partial C_{\mathrm{F}}}{\partial t} .
$$

The boundary conditions for convective heat transfer and mass transfer at the leather surface are

and

$$
q=h_{\mathrm{e}}\left(T_{\mathrm{e}}-T\right)
$$

$$
\bar{m}=h_{\mathrm{m}}\left(C_{\mathrm{e}}-C_{\mathrm{A}}\right) \text {. }
$$

The deriving force determining the rate of mass transfer inside the fabric is the difference between the relative humidities of the air in the pores and the leather. In this study, the rate of moisture exchange is assumed to be proportional to the relative humidity difference. Thus, the rate equation for mass transfer is

$$
\frac{1}{\rho(1-\varepsilon)} \frac{\partial C_{\mathrm{F}}}{\partial t}=K\left(y_{\mathrm{A}}-y_{\mathrm{F}}\right) .
$$

Also, the relative humidities of air and leather are assumed to be

$$
y_{\mathrm{A}}=\frac{C_{\mathrm{A}} R T}{P_{\mathrm{s}}}
$$

and

$$
y_{\mathrm{F}}=\frac{C_{\mathrm{F}}}{\rho(1-\varepsilon)} .
$$

The rate constant in Equation 5 is an unknown empirical constant and the effect of this constant can be examined. The value of the rate constant was varied from $K=0.1$ to $K=10$. The resulting calculated leather surface temperatures are compared in Figure 1.

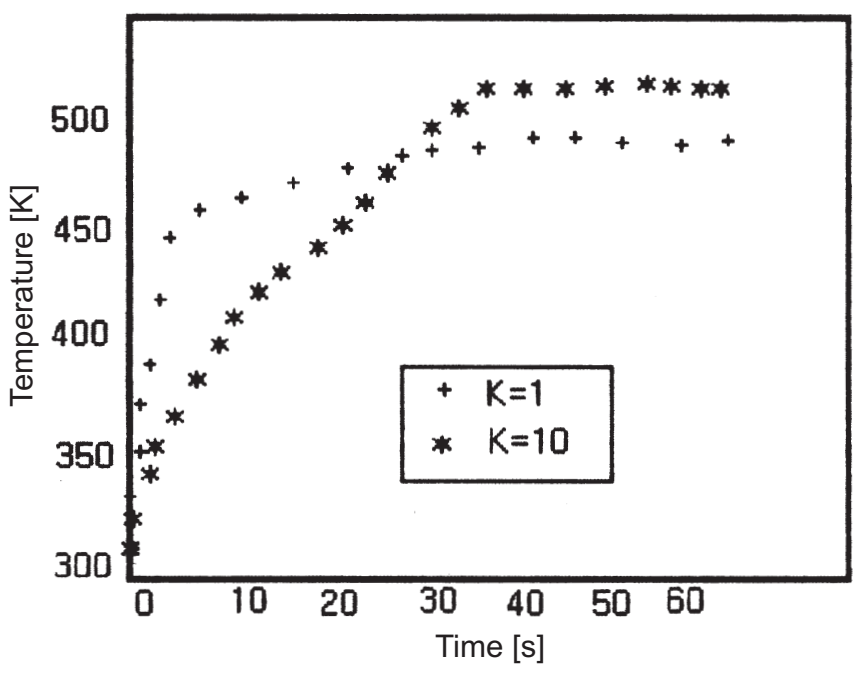

Fig. 1: Effect of rate constant on the leather surface temperature

When the rate constant is small, the evaporation rate is so small that the moisture content decreases very slowly. Initially, the surface temperature increases rapidly, but later this declines. When $K$ is greater than 1.0, however, the effect of the rate constant on the surface temperature distribution is not 
significant. This indicates that when the rate constant is greater than 1.0, the evaporation rate is high and the drying process is mainly controlled by the moisture diffusion mechanism inside the fabric. Thus we have assumed the rate constant to be 1.0 in the following calculations.

\section{Model prediction}

The temperature and moisture content were calculated using this model. In these calculations, the parameters used for the base condition are shown in Table 1.

Table 1: Values of parameters for base condition

\begin{tabular}{|l|c|c|}
\hline \multicolumn{1}{|c|}{ Parameter } & Unit & Value \\
\hline Dryer Temperature & $\mathrm{K}$ & 450.00 \\
\hline Heat Transfer Coeff. & $\mathrm{W} / \mathrm{m}^{2} \mathrm{~K}$ & 70.00 \\
\hline Mass Transfer Coeff. & $\mathrm{m} / \mathrm{s}$ & 0.08 \\
\hline Leather Thickness & $\mathrm{mm}$ & 1.20 \\
\hline Porosity & - & 0.90 \\
\hline Initial Moisture & $\% \mathrm{RH}$ & 50.00 \\
\hline Drying Air Moisture & $\mathrm{kg} / \mathrm{m}^{3}$ & 0.02 \\
\hline
\end{tabular}

First, the transient temperatures of the surface and center of the leather were calculated, using the data shown in Table 1. From Figure 2, we see that the surface and center tem-

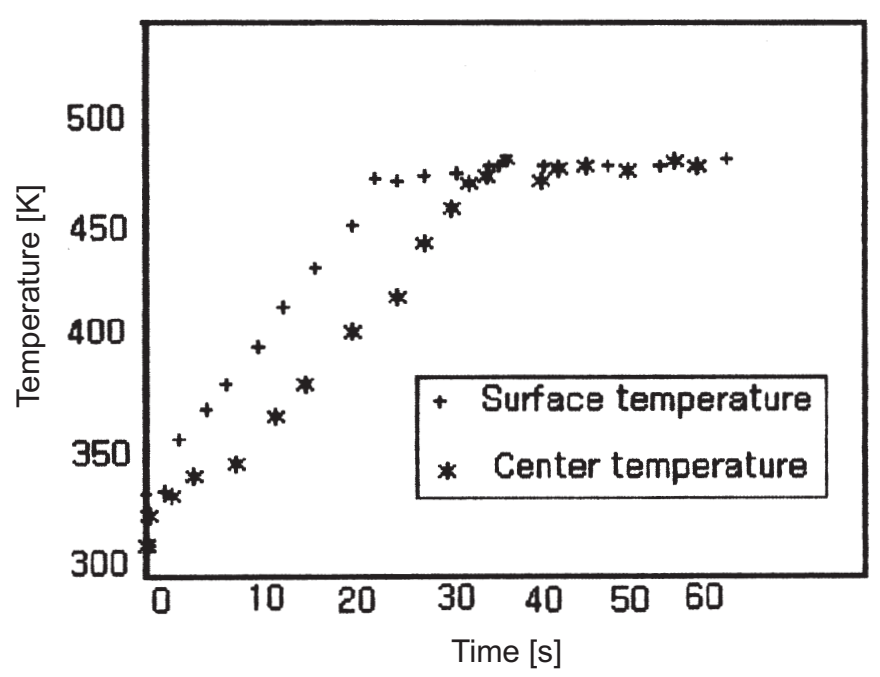

Fig. 2: Temperature variation of surface and center of leather

perature increase rapidly in the initial stage up to the saturation temperature, at which point the moisture in the leather starts to evaporate. From that point, the difference between the surface temperature and the center temperature increases due to the different moisture contents of the surface and the center. In this stage, the leather starts to dry from the surface, and the moisture in the interior is transferred to the leather surface. Then the moisture content decreases during drying of the leather. Thereafter, the surface and center temperatures converge to reach the external air temperature.

The moisture variations of the surface and the center of the leather were also calculated and are shown in Figure 3. Initially, the surface moisture content decreases rapidly, but later this rate declines because moisture is transferred to the

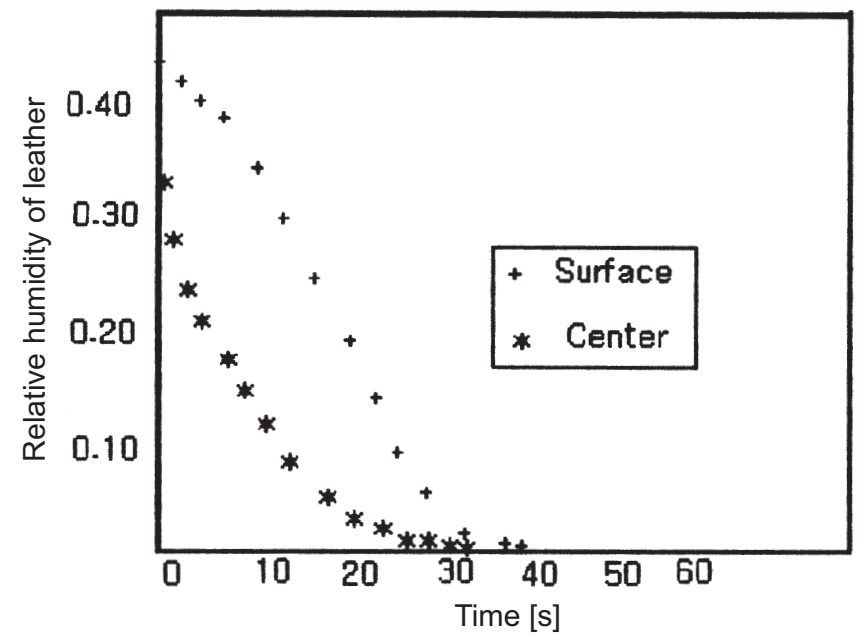

Fig. 3: Moisture content of surface and centre of leather

external air from the leather surface. The center moisture content remains constant for a short time, and then decreases rapidly because the moisture content difference between the surface and the interior of the leather becomes large. After drying out, both center and surface moisture contents converge to reach the external air moisture content.

The mathematical model is used to predict the effects of many parameters on the temperature variation of the leather. These parameters include the operation conditions of the dryer, such as the initial moisture content of the leather, heat and mass transfer coefficients, drying air moisture content, and dryer air temperature.

Figure 4 shows the calculated results of the effect of the initial moisture content of the leather. When the initial moisture content is high, the temperature rise is relatively small and drying takes a long time. This may be because the higher moisture content needs much more heat for evaporation from the leather. Also, the saturation temperature for higher moisture content is lower, and thus the temperature rise in the initial stage is comparatively small.

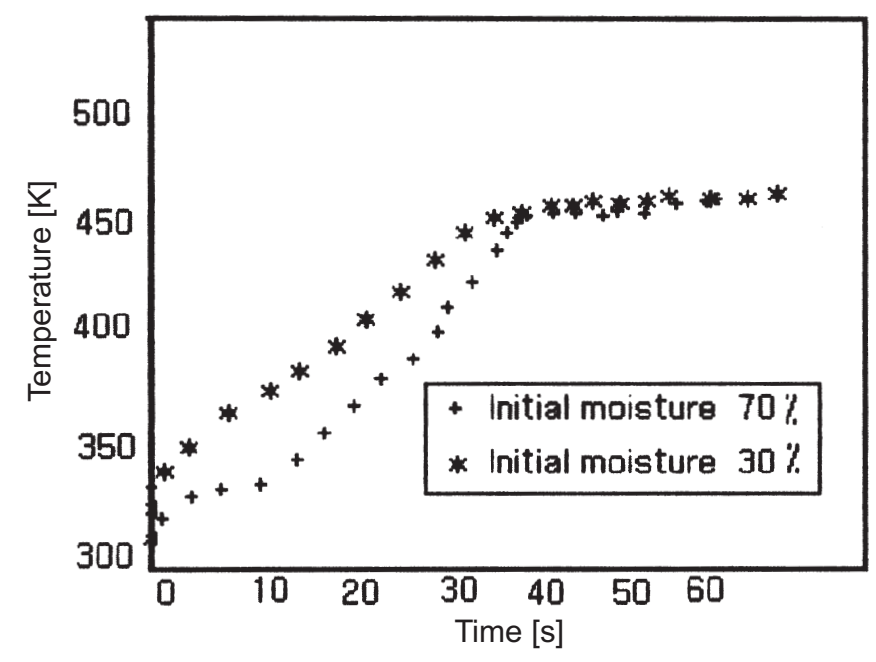

Fig. 4: Effect of initial moisture content of fabric

The leather temperature was calculated to investigate the effect of heat and mass transfer coefficients in these calculations. An analogy was assumed between heat and mass 


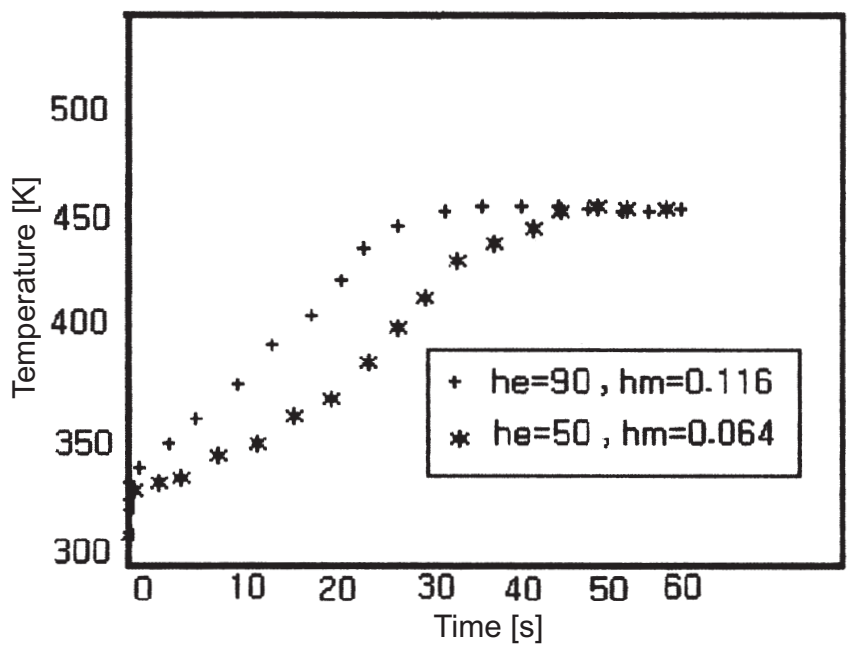

Fig. 5: Effect of heat and mass transfer coefficients

transfer, and both heat and mass transfer coefficients were determined using this assumption. The calculated results are compared in Figure 5. When the heat and mass transfer coefficients are high, the leather temperature rise is great and the time required for drying is relatively short.

The effect of drying air moisture content, and the calculated results of the model are shown in Figure 6. When the moisture content is high, the initial temperature rise of the leather also becomes high. This may be because the saturation temperature in the initial stage largely depends on the drying air moisture content. After the initial temperature rise, however, the temperature increase is relatively small, and thus the time required for complete drying is comparatively long.

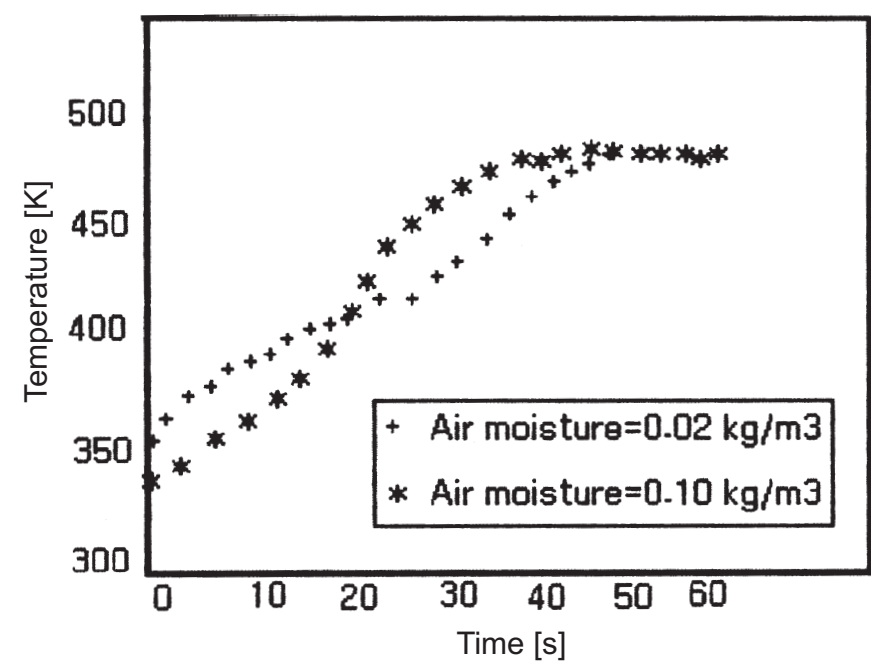

Fig. 6: Effect of drying air moisture content

The effect of dryer air temperature was also investigated, and the calculation results are shown in Figure 7. When the dryer air temperature is high, the temperature rise of the leather is great.

\section{Conclusion}

The mathematical model developed in this study can be used to predict transient variations in temperature and

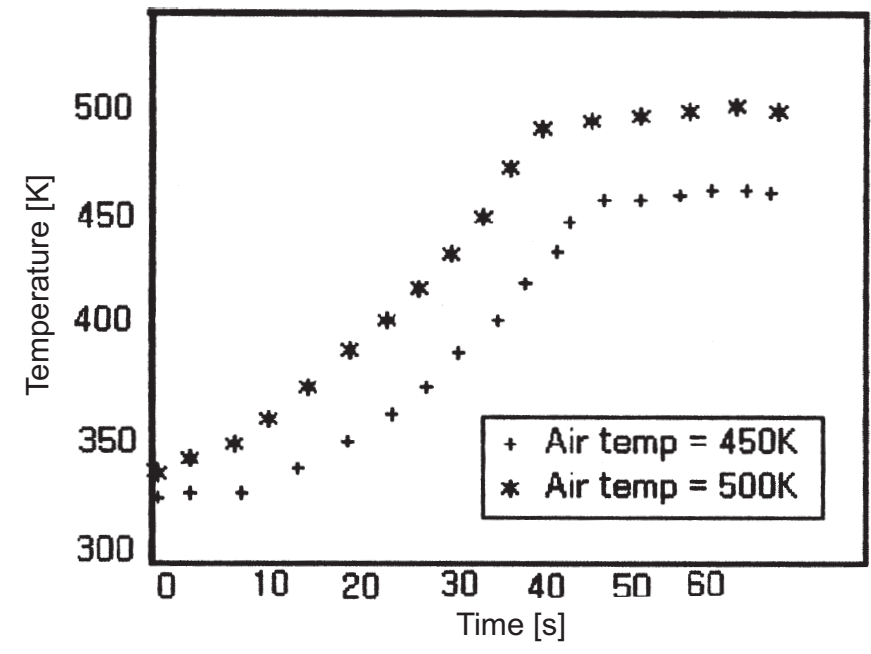

Fig. 7: Effect of dryer air temperature

moisture content distribution of leather in the dryer with reasonable accuracy using the model, the effect of the temperature and humidity of the dryer, the initial moisture content of leather and the heat and mass transfer coefficients can be predicted for leather. With the model predictions, energy consumption can potentially be reduced by optimizing the drying conditions of the dryer.

\section{Nomenclature}

$C_{\mathrm{A}} \quad$ moisture content of air in leather pores $\left[\mathrm{kg} / \mathrm{m}^{3}\right]$

$C_{\mathrm{e}} \quad$ moisture content of external air $\left[\mathrm{kg} / \mathrm{m}^{3}\right]$

$C_{\mathrm{F}} \quad$ moisture content in leather $\left[\mathrm{kg} / \mathrm{m}^{3}\right]$

$C_{\mathrm{p}} \quad$ specific heat $[\mathrm{kJ} / \mathrm{kg} \mathrm{K}]$

$D$ diffusion coefficient $\left[\mathrm{m}^{2} / \mathrm{s}\right]$

G mass flowrate $\left[\mathrm{kg} / \mathrm{m}^{2} \mathrm{~s}\right]$

$h_{\mathrm{e}} \quad$ heat transfer coefficient $\left[\mathrm{W} / \mathrm{m}^{2} \mathrm{~K}\right]$

$h_{\mathrm{m}} \quad$ mass transfer coefficient $[\mathrm{m} / \mathrm{s}]$

$K \quad$ rate constant [1/s]

$\mathrm{k}$ thermal conductivity [W/m K]

$\bar{m} \quad$ mass transfer rate $\left[\mathrm{kg} / \mathrm{m}^{2} \mathrm{~s}\right]$

$P_{\mathrm{s}} \quad$ saturation pressure $[\mathrm{Pa}]$

$q \quad$ convective heat transfer rate $\left[\mathrm{W} / \mathrm{m}^{2}\right]$

$R \quad$ gas constant $[\mathrm{kJ} / \mathrm{K}]$

$T$ temperature [K]

$T_{\mathrm{e}} \quad$ external air temperature [K]

$t \quad$ time [s]

$y_{\mathrm{A}} \quad$ relative humidity of air in pores of leather

$y_{\mathrm{F}} \quad$ relative humidity of leather

$\varepsilon \quad$ porosity

$\lambda \quad$ latent heat of evaporation $[\mathrm{kJ} / \mathrm{kg}]$

$\rho \quad$ density $\left[\mathrm{kg} / \mathrm{m}^{3}\right]$ 


\section{References}

[1] Arma, C. R., Gortary, J. C.: Experimental data and preliminary design of a non-conventional dryer of leather. Sixth int. Drying Symp., IDS 85, Versailles, France, 1988, pp. 59-63

[2] Bienkiewicz, K. J.: Physical Chemistry of Leather Making. Robert E. Kriger publication Co., 1983

[3] Tomas, S., Skansi, D., Sokele, M.: Drying Technology. Vol. 11, No. 6/1993, p. 1353

[4] Skansi, D. et al: Experimental Evaluation of the Microwave Drying of Leather. Journal of the Society of Leather Technologists and Chemists, Vol. 79, 1993, pp. 171-177

[5] Beard, J. N.: More Efficient Tenter Frame Operations Through Mathematical Modeling. Textile Chem. Colorist, No. 3/1976, pp. 47-50

[6] Carnahan, B., Luther, H. A., Wilkes, J. O.: Applied Numerical Method. John Wiley \& Sons, NY, 1969
[7] Farnworth, B.: A Numerical Model of Combined Diffusion of Heat and Water vapor Through Clothing. Textile Res. J., No. 56/1986, pp. 653-655

[8] Henry, P. S.: Diffusion in Absorbing Media. Proc. R. Soc., 171A, 1986, pp. 215-655

[9] Nordon, P., David, H. G.: Coupled Diffusion of Moisture and Heat in Hygroscopic Textile Materials. Int. J. Heat Mass Trans., No. 10/1967, pp. 853-866

[10] Treybal, R. E.: Mass Transfer Operation. $2^{\text {nd }}$ ed., Mc Graw-Hill Book Co., 1968

Dr A. K. Haghi

e-mail: Haghi@Kadous.gu.ac.ir

University of Guilan

P.O.Box 3756

Rasht, IRAN 